\title{
The Household Enterprise Sector in Ghana: Overview and Challenges
}

\author{
Danny Turkson ${ }^{1} \&$ Emmanuel A. Codjoe ${ }^{2}$ \\ ${ }^{1} \mathrm{PhD}$. Student, Economics Department, University of North Carolina at Greensboro, USA \\ ${ }^{2}$ Lecturer, Economics Department, University of Ghana, Ghana \\ Correspondence: Danny Turkson, Bryan School of Business and Economics, University of North Carolina at \\ Greensboro, USA. E-mail: d_turkso@uncg.edu
}

Received: May 27, 2020

doi:10.5539/ijbm.v15n8p140
Accepted: June 22, 2020

Online Published: July 26, 2020

URL: https://doi.org/10.5539/ijbm.v15n8p140

\begin{abstract}
Household Enterprises (HEs) have not received much consideration in the enterprise literature even though they are crucial for the development of an economy. These enterprises have been the main source of livelihood for most families in the informal sector and their contribution to reduction in unemployment is pivotal to growth of developing economies. This paper explores the nature of HE sector in Ghana and the challenges they face in their daily operations. The study employed an informal enterprise survey of 729 household enterprises conducted in 2013 by the World Bank in Ghana. With the use of systematic review and descriptive analysis, the study outlined financial constraint as the main challenge faced by HEs and discussed the linkage between HEs and the financial sector in Ghana. Based on these findings recommendations were made to the major stakeholders in the sector (entrepreneurs, financial institutions and government).
\end{abstract}

Keywords: Household Enterprises (HEs), sector, Ghana

\section{Introduction}

\subsection{Definition of Household Enterprises (HEs)}

Household Enterprises (HEs) have not received much consideration in the enterprise literature even though they are crucial for the development of an economy. The definition of HE remains varying or unclear (Kayanula and Quartey, 2000). It is a matter of literature. The inconsistency in the definition of HE may lead to complications in the calculation of income and assets, and also the rate of return on HE (Samphantharak \& Townsend, 2012). Kayanula and Quartey (2000) stated that: "There is no single, universal, or uniformly acceptable definition of enterprises" (p.225).

Therefore, quite a number of criteria have been employed to help define HE. A review of the literature on the definitions of $\mathrm{HE}$ is based on diverse criteria such as the number of workers employed (household members employed), the proportion of returns to the household, and the value of fixed assets. To classify a business as a HE, standard practice (International Labour Organisation [ILO], 2011) obliges that the following conditions have to be met:

a) The ownership condition (owned by a member of the household) and at least

b) The size criteria (limit of the number of employees), or

c) The legal status (non-registration of the enterprise or its workers).

The last criterion (legal status) is mostly inconsistent since the rules on the registration of enterprises vary by country. The word 'registration' may also differ in meaning depending on the country. For example, in Uganda, registration means a certain level of legitimacy from the state, but this is not the case in Tanzania and Rwanda. Also, in some countries, it is legal to do business in an individual's own name even without registering. Therefore, it is only the first two criteria that are mostly used by most researchers in order to maintain consistency (Fox \& Sohnesen, 2012). The World Bank in collaboration with Women in Informal Employment: Globalising and Organising (WIEGO) on a study on Policies and Programmes for Household Enterprises in Africa defined HE as: "Self-employed persons together with any family members or casual workers assisting them (not involving contractual workers)" (WIEGO, 2008, p.1). According to the World Bank (2012), HEs are self-employed enterprises working in non-agriculture, which may employ contributing family workers. It also stated that HEs together with Micro Enterprises (MEs) form what is known as Non-farm Enterprises (NFEs). 
Narrowing down to developing countries, Fox and Sohnesen (2012) examined Household Enterprises in Sub-Saharan Africa (SSA), and they sometimes used HEs and MEs interchangeably. This is because they had a lot of characteristics in common: both are independent household owned non-farm enterprises. The distinction is that HEs employ only family workers whereas MEs employ at least one non-family employee on a constant or contractual basis. The NBS of Nigeria also defines HE as a self-employment business that employs about 5 workers (NBS, 2011). A Household Enterprise as described by Bakeine (2009): "HEs consist of self-employed (or own-account) workers and unpaid family members engaged in non-farm business activities, at the lower end of what is often categorized as micro, small and medium enterprises (MSMEs)" (p.3).

This implies that HEs represent the bottom of the pyramid of MSEs, therefore in some studies they were known as Micro Enterprises (MEs) as shown in Fig.1 below. In conclusion, there is no general consent over the definition of a HE. Since the definitions vary across countries, it is vital to look at definitions of HEs in the context of Ghana.

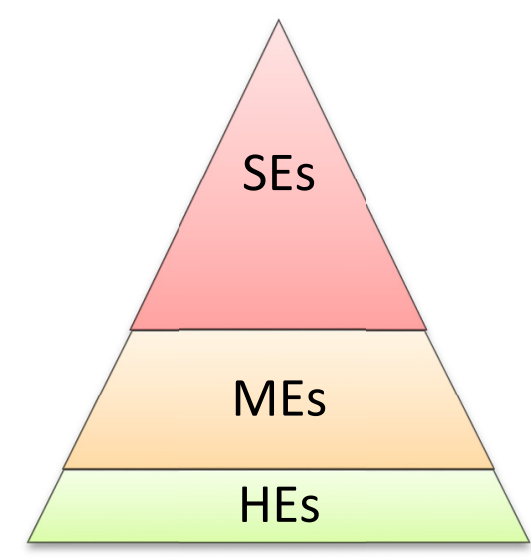

Figure 1. Cross-section pyramid of micro and small scale enterprise (MSE)

\subsection{Definition of HE in Ghana}

In Ghana, the definition of $\mathrm{HE}$ is based on the classification of enterprises. Some studies use turnover level and skill of labour while others make use of capital asset in the categorisation of enterprises (Abor \& Quartey, 2010). The classification of HE in Ghana has mainly been based on the criteria of size and ownership. Size has been well-defined in diverse ways like annual turnover, industry of enterprise and number of workers (Weston \& Copeland, 1998). But in most studies in Ghana, size has usually been defined as the number of employees. For example, a survey report of the Regional Project on Enterprise Development Ghana categorized enterprises into: (i) less than 5 workers - microenterprise; (ii) 5-29 workers - small enterprise; (iii) 30-99 workers - medium enterprise (iv) 100 and above - large enterprise (Abor \& Quartey, 2010).

Furthermore, what explicitly defines HE from the various enterprises is ownership. According to the Ghana Statistical Service (GSS), HEs are non-farm enterprises owned by a household. It also considers the proportion of the returns of the enterprise that comes to the household (GSS, 2014). The Living Standards Measurement Study (LSMS) by EGC-ISSER (2015) also follows the definition of GSS. In addition, a World Bank study on HEs in Ghana stated that: "HEs are small businesses engaged in nonfarm activity, and are operated by a single individual (the owner) or with the assistance of family members or no more than five non-family workers on a casual basis" (Quainoo, 2011, p. 1). Fox and Sohnesen (2012), on their examination on HEs in Ghana, defined $\mathrm{HE}$ as a non-farm enterprise that is owned by a household and unincorporated, with only family workers. The above did not indicate a cut off for the number of employees but one thing is certain, the employees should be members of the household and causal workers but not permanent contractual workers.

\subsection{General Overview of HEs in Ghana}

In Ghana, 44.3 percent of households are engaged in non-farm enterprises, of which 50.4 percent are in urban communities. As stated in the GLSS report, these enterprises are classified into major groups (Manufacturing, Trading, and Other Activities) according to the United Nations Statistical Classification System called the International Standard Industrial Classification of all Economic Activities (ISIC), Revision 4 (GSS, 2014). The common operations within this sector comprise of soap and detergents, fabrics, textile and leather, cement and 
bricks, village blacksmiths and tinsmithing, ceramics, beverages, food processing and bakeries, tailoring and clothing, wood furniture, electronic assembly, agro-processing, mining and timber, mechanics, chemical-based products, but does not involve farming, fishing, hunting and forestry (Kayanula \& Quartey, 2000; Abor \& Quartey, 2010; Quainoo, 2011).

The HEs are also classified based on the number of years they have been in operation. A study by Abor and Biekpe (2006) categorised them in this manner:

(i) Infant - less than 1 year.

(ii) Young - from 1 to 5 years.

(iii) Adult - from 6 to 10 years.

(iv) Mature -10 years and over.

The majority of HEs in Ghana are not formally registered. Most of HEs run by females are more likely to operate from the home. The HEs owned by females are likely to be overlooked since they are home-based and do not operate directly in the traditional market. Therefore, these owners tend to be invisible entrepreneurs. Household savings is the main source of capital for HEs. After household savings, is assistance from friends or relatives, and then followed by the banks (GSS, 2014). HEs are usually more labour-intensive, and more efficient in developing countries like Ghana where labour is abundant and capital is scarce. Most of these HEs operate with low technological know-how and innovation.

In addition, income generated by the financial and physical capital of HEs cannot be straightforwardly separated from that generated by the human capital of members of the household (wage earnings). Also, they are not secured by limited liability, therefore, the owners are not different entities from their enterprises. This affirms what was established by Samphantharak and Townsend (2012) that, business assets and household assets are legally inseparable, therefore they are collectively used between household and business.

Another characteristic of HEs in Ghana is that their products and services are delivered to only the local market. They lack the ability to access the international market even if they wanted to. This is mainly because of the massive capital requirement for operating in the export market, low level of education, informal nature of the business, and lack of training for entrepreneurs (Gariba, 2015). The lack of entry barriers has created competition which has led to the closure of inefficient and poorly managed HEs, making the HEs in the trading (retail) sector face the highest closure risks. Nevertheless, because of higher capital and skill requirements in the manufacturing sector, it has made it less competitive (GSS, 2014). The HEs in services and manufacturing are more likely to grow than those in trading.

\subsection{Contribution of HEs to Economic Growth and Development}

In the early 2000s, there has been a resurgence of economic growth and development in low-income SSA countries, including Ghana. Fox and Sohnesen (2012) postulated that, between the years of 2000-2008, countries like Ghana, Rwanda, Mozambique, Uganda, and Tanzania all recorded GDP per capita growth above 3 percent per annum. This growth was partly attributed to the increase in non-farm private enterprise employment, which included owners and family members in HEs.

Household Enterprises creates most of the new jobs outside of agriculture (GSS, 2014). The movement of labour outside of the agricultural sector in the recent decade shows up as HE employment, and just a little showing up as wage employment. The principal reason for the increase in HE employment over the previous years was due to the debt crisis, during which many developing countries underwent a laying off of workers in the public sector, and the private sector was not capable of absorbing the growing labour force (Fox \& Gaal, 2008). Employment in HEs of SSA countries undergoing growth and poverty reduction is the rapid growing part of such economies. These enterprises have been the key solution to diversification by transforming labour from subsistence agriculture to non-agriculture activities (World Bank, 2012). In Ghana, the GSS (2014) stated in the GLSS report that, more than six million people are engaged in non-farm enterprises, including both HEs and MEs.

Another key contribution of the HEs to both developed and developing countries is poverty alleviation and diversification of income. Although 40 percent of household rely on HEs as an income source, they (HEs) are often disregarded in low-income SSA development strategies (Fox \& Sohnesen, 2012). This is because the majority of the informal enterprises are often believed to be unproductive, hence described as a poverty trap. Contrary to this assertion, a study by Barrett, Reardon and Webb (2001) evaluated household livelihoods in rural SSA and concluded that HEs (non-farm activities) aided in the reduction of household poverty. It was also noted by Fields (2012) that, the only way for poor households in SSA to eradicate poverty is by earning more money 
from employment. He further argued that most non-farming employment in SSA countries like Ghana is now in HEs and has helped alleviate poverty.

In Ghana, the majority of HEs in rural areas are often seasonal ventures, since investments in the agricultural sector (farming) have not reduced risk or increased productivity enough for households to particularly specialize in one sector or the other (Fox \& Sohnesen, 2012). This enables poor households to diversify their income, leading to a rise in income and making them less poor.

\subsection{Policies, Institutional and Support Environment for HEs}

Household Enterprise improvement campaign in Ghana was not a major priority of the government during the 1960s and 1970s. This is because, during the first republic era (1960-1966), the president (Dr. Kwame Nkrumah) emphasized on policies in the direction of industrialisation and modernisation at the state level but did not support the micro domestic indigenous sector. The economic crunch (high inflation) that hit Ghana in the early 1980s pushed numerous employees in the formal sector into alternative self-employment in order to make a decent income (Kayanula \& Quartey, 2000). Self-employment and small scale enterprise employment recorded 2.9 percent growth per annum; this was more than that of employment growth in large firms (Steel \& Webster, 1991).

The government then got interested in the expansion of the small business sector. The National Board for Small Scale Industries (NBSSI) was also established in 1985, to cater for the needs of small businesses; this was through training programs such as the Entrepreneurial Development Programme, which is aimed at training and assisting individuals with potential entrepreneurial capabilities into self-employment (Kayanula \& Quartey, 2000).

A Mutual Credit Guarantee Scheme was established for entrepreneurs, who for the reason of no collateral could not access bank loans, to access loans. Also, a Rural Finance Project was established to provide long-term loans for craftsmen and small-scale farmers (Kayanula \& Quartey, 2000). The National Vocational and Training Institute (NVTI) was also founded by the government to train and enhance the skills of elementary and secondary school leavers, and such other people through master craftsmanship, apprenticeship and career development (NVTI, 2009). The World Bank in collaboration with the Programme of Action to Mitigate the Social Costs of Adjustment (PAMSCAD) made special funds available to support microenterprises in accumulating finances. This was founded on the belief that, the main reason why the private sector had not grown as it should have was because of unavailability of loans from the formal financial institution (Abor \& Biekpe, 2006).

In recent times, the National Committee on the Informal Economy (NCIE) support HEs through the Business Advisory Centres (BACs) and the local authorities such as Metropolitan, Municipal and District Assemblies (MMDAs). The BACs main responsibilities are, to support them in the form of training and counseling in areas like record-keeping, preparation for the NVTI professional tests, visiting other HEs to learn from them and also to encourage HEs to form their own associations (Quainoo, 2011). The MMDAs are responsible for zoning and giving HEs a workplace in places like the local market area and they also undertake local training with the aim to build the capacity of HE operators. Some of the training programs are; handicrafts making, shea butter extraction, livestock rearing, soap making, among others (Quainoo, 2011). The challenge encountered with the implementation of these policies is that they require complex legal processes to be eligible for the package they come with. Also, many of the loan schemes are mostly centralised in the capital cities like Accra and Kumasi, making it difficult for rural-based HEs to access (Baah-Nuakoh, 2003).

\section{Nature of the HEs in Ghana}

This study employed the World Bank's Informal Enterprise Survey (IFS) in Ghana for the year 2013. This is a survey that covered non-agricultural enterprises which are informal and privately owned by households. By informal, they are enterprises that are not registered with the Registrar's General Department. The data fits the description of a HE according to the ILO (2011). The World Bank's IFS used a stratified sampling technique. Enterprises were stratified based on the sector of activity and geographical location. The sectorial stratification was designed as follows: four manufacturing sectors (food and beverages, chemicals and plastics, textiles and garments, other manufacturing) and two service sectors (retail and other services). For geographical location, enterprises were stratified based on the distribution of economic activities taking place in the four main regional urban centres namely; Accra, Tema, Takoradi, and Northern Sector (Kumasi and Tamale). The regions were then divided into 180 zones where at least four enterprises were randomly sampled per zone. A total of 729 enterprises were surveyed. The distribution of the enterprises among the four regions is as follows: Accra 176, Northern Sector (consisting of Kumasi and Tamale) 189, Takoradi 180 and Tema 184. 
This section gives a detailed statistical distribution and overview of some variables of the HE sector in Ghana based on the World Bank's Informal Enterprise Survey (as shown in Table 1).

Owner's Age: To begin with, the owner's age distribution of the survey ranges from 18 years to 80 years with an average age of about 39 years. The majority (over $50 \%$ ) of the entrepreneurs were between 31 to 45 years, with just about 5\% who were above 60 years of age. Approximately $23 \%$ and $21 \%$ were in the age brackets $18-30$ years and 46-60 years respectively.

Household Size: The household size of the entrepreneur ranges from 1 to 65 people with an average of approximately 6 people. Most of the households were within the size bracket of 1-5 people (approximately 59\%), followed by 6-10 people (approximately 36\%) and finally those households with size more than 10 people are just about $5 \%$.

Owner's Experience: The entrepreneurs' experience average 8 years which ranges from no experience (0 years) to 50 years of experience. The majority (about $44 \%$ ) of the entrepreneurs were in the range of $0-5$ years of experience, followed by $6-10$ years and more than 10 years which approximated $26 \%$ and $30 \%$ respectively.

Table 1. Descriptive Statistics and overview of some variables of the HE sector in Ghana

\begin{tabular}{|c|c|c|c|c|c|}
\hline Continuous Variables & $\begin{array}{l}\text { Number of Enterprises } \\
(\mathrm{N}=729)\end{array}$ & Percentage (\%) & Min & Max & Mean \\
\hline Owner's Age & & & 18 & 80 & 39.44 \\
\hline - $\quad 18-30$ years & 171 & 23.46 & & & \\
\hline - $31-45$ years & 370 & 50.75 & & & \\
\hline - $\quad 46-60$ years & 151 & 20.71 & & & \\
\hline - $\quad 60+$ years & 37 & 5.08 & & & \\
\hline Household Size & & & 1 & 65 & 5.72 \\
\hline - $\quad 1-5$ people & 429 & 58.85 & & & \\
\hline - 6-10 people & 265 & 36.35 & & & \\
\hline - $\quad 10+$ people & 35 & 4.8 & & & \\
\hline Owner's Experience & & & 0 & 50 & 8.49 \\
\hline - $0-5$ years & 320 & 43.90 & & & \\
\hline - $6-10$ years & 191 & 26.20 & & & \\
\hline - $10+$ years & 218 & 29.90 & & & \\
\hline Number of Household Workers & & & 0 & 10 & 0.64 \\
\hline - $\quad 0$ member & 426 & 58.44 & & & \\
\hline - $1-3$ members & 292 & 40.05 & & & \\
\hline - $\quad 4-10$ members & 11 & 1.51 & & & \\
\hline HE age & & & 0 & 53 & 8.50 \\
\hline - Infant: less than $1 \mathrm{yr}$ & 20 & 2.74 & & & \\
\hline - Young: 1-5years & 321 & 44.03 & & & \\
\hline - Adult: 6-10years & 201 & 27.57 & & & \\
\hline - Mature: $10+$ years & 187 & 25.65 & & & \\
\hline HE size & & & 1 & 30 & 2.29 \\
\hline - 1 worker & 337 & 46.23 & & & \\
\hline - $\quad 2-5$ workers & 349 & 47.87 & & & \\
\hline - $5+$ workers & 43 & 5.90 & & & \\
\hline Dummy Variables & $\begin{array}{l}\text { Number of Enterprises } \\
(\mathrm{N}=729)\end{array}$ & $\begin{array}{l}\text { Percentage } \\
(\%)\end{array}$ & & & \\
\hline \multicolumn{6}{|l|}{ Gender } \\
\hline - $\quad$ Male & 271 & 37.17 & & & \\
\hline - $\quad$ Female & 458 & 62.83 & & & \\
\hline \multicolumn{6}{|l|}{ Marital Status } \\
\hline - $\quad$ Married & 470 & 64.47 & & & \\
\hline - $\quad$ Otherwise & 259 & 35.53 & & & \\
\hline \multicolumn{6}{|l|}{ Education } \\
\hline - $\quad$ High education & 309 & 42.39 & & & \\
\hline
\end{tabular}




\begin{tabular}{lrr}
\hline - Low education & 420 & 57.61 \\
Diversification & & \\
- Diversified & 31 & 4.25 \\
- Not diversified & 698 & 95.75 \\
Sector & & \\
- Manufacturing & 365 & 50.07 \\
- Retail \& Services & 364 & 49.93 \\
Base of Operation & & \\
- Home-Based & 144 & 19.75 \\
- Otherwise & 585 & 80.25 \\
Financial Records & & \\
- Records & 240 & 32.92 \\
- No records & 489 & 67.08 \\
Savings Account & & \\
- Holds account & 293 & 40.19 \\
- No account & 436 & 59.81 \\
Asset & & \\
- Owns Asset & 295 & 40.47 \\
- Otherwise & 434 & 59.53 \\
\hline Source: Author's compilation based on IFS (2013).
\end{tabular}

Source: Author's compilation based on IFS (2013).

Number of Household Workers: The number of household workers range from 0 to 10 members, with an average of approximately 1 member. 426 enterprises (about 58\%) employed no household member, 292 enterprises (about 40\%) employed 1 to 3 members and 11 enterprises (about 2\%) employed 4 to 10 members of their household.

HE age: The survey showed that age of the enterprise ranges from less than a year old to 53 years with an average of 8 and half years. The study then followed the categories used by Abor and Biekpe (2006) to further group them. There were $2.74 \%$ infant enterprises (less than 1 year), $44.03 \%$ young enterprises ( 1 to 5 years), $27.57 \%$ adult enterprises (6 to 10 years) and $25.65 \%$ matured enterprises (more than 10 years). This distribution of the age of the enterprise confirms the results of Fox and Sohnesen (2012) which indicated that survival of HEs tends to reduce as the enterprise approaches maturity.

HE size: the enterprises averaged a size of 2 workers. 337 enterprises (approximately 46\%) were sole proprietor (1 worker), 349 enterprises (approximately 48\%) were small HEs (2 to 5 workers) and only 43 enterprises (approximately 6\%) were big HEs (more than 5 workers).

Gender: The survey results show that there are 37.17\% male-owned enterprises and $62.83 \%$ female-owned enterprises.

Marital Status: The survey shows that 470 (about 64\%) of the entrepreneurs are married.

Education: The results of the survey also categorizes education into five main groups which are no education $(13 \%)$, basic education (45\%), secondary education (30\%), vocational education $(8 \%)$ and tertiary education (4\%). But for the sake of this study, education was categorized into high education (secondary, vocational and tertiary education) and low education (no education and basic education).

Diversification: From the survey, the majority (approximately 95\%) of the entrepreneurs are not diversified. This confirms the findings of previous studies (Haggblade, Hazel, \& Reardon, 2010; Fox \& Sohnesen, 2012) which indicate that HEs often serves as the only or main source of livelihood for most of the household of the entrepreneurs.

Sector: The survey covered an approximately equal number of enterprises in manufacturing, and retail and services sectors; 365 and 364 respectively. Those in the retail and services sector have a higher rate of access to loans (approximately 47\%) than those in the manufacturing sector.

Base of Operations: The survey revealed that 585 enterprises (about 80\%) are market-based whereas 144 enterprises $(20 \%)$ are home-based.

Financial Records: Just about 33\% of the enterprises kept records. This supports the findings of Samphantharak and Townsend (2012) which states that most HEs do not keep any financial records and keep their operations at 
the informal level.

Savings Account: In addition to the fact that they operate at the informal level, they do not have bank accounts for the operations of the enterprise. The survey showed that about $60 \%$ do not have a saving account and just $40 \%$ of the HEs save with formal financial institutions.

Asset: Concerning assets ownership, the majority (approximately 60\%) of the HEs do not own assets. The assets in this survey entailed machinery and vehicles. Among the 295 (about 40\%) enterprises that own assets, 182 (about 62\%) of them own machinery, 72 (about 24\%) own vehicles and 41 (about 14\%) own both machinery and vehicle.

\section{Problems Facing Household Enterprises (HEs)}

This section reports on the challenges most HEs face in starting and the daily running of their businesses.

\subsection{Inadequate Capital and Lack of Finance}

Inadequate capital and lack of finance are the challenges repeatedly mentioned by most HEs (GSS, 2014). It covers the several challenges confronted by HEs in their daily operations as well as the following: (i) inability to acquire a suitable worksite; (ii) difficulties in securing tools and material inputs; (iii) high cost of raw materials; (iv) inability to meet customer demands; (v) high costs of utilities and fuel.

The challenge of lack of finance includes a circumstance where HEs experience hitches in starting and in running the affairs of the business due to delays or failure to obtain loans. Many HEs try but fail to obtain loans from formal financial institutions. Even those granted the loans, encountered a lot of complexities in the process. A World Bank study showed that 71 percent of the urban HEs and 65 percent of the rural HEs reported difficulties in accessing loans. In all, 68 percent of all entrepreneurs surveyed claimed to be experiencing difficulties in acquiring finance for their businesses (Bakeine, 2009). The main difficulties faced in their effort to access loans include finding acceptable collateral; very high interest rate; the maximum loan size allowed for micro businesses being too small; the loan process is too long and tedious to deliver the required funds at the time needed; and the repayment terms being unfavourable (Stephanou \& Rodriguez, 2008; Bakeine, 2009; Alhassan \& Sakara, 2014). Resulting from the inability to raise finance, numerous HEs survive on a very insignificant capital base and ultimately collapse. Because of this, many HEs resort to the informal sector, including borrowing from friends and relatives to accumulate some capital (Nkuah, Tanyeh, \& Gaeten, 2013; GSS, 2014). In several cases these alternatives fail to deliver, and should they even deliver, they only make available just a fraction of what the enterprise actually needs.

\subsection{Poor Infrastructure}

The problem of poor infrastructure entails HEs experiencing poor road network and inconsistencies in power supply. The problem of access, reliability, and cost of electricity (power) in Ghana is a critical challenge particularly among HEs in the manufacturing, services, and trade (retail) sectors. Whereas rural based HEs are almost always affected by inaccessibility to electricity, urban HEs may have access to electricity but are affected by the unreliable nature of the supply and high cost of electricity (Bakeine, 2009). The direct consequences of this problem on HEs' operations are lost employment and a decline in income. The common remedy most of the HEs resort to is buying generators to operate their business. This often is out of their reach since the cost of buying and maintaining a generator is expensive and therefore most of the enterprises' production reduces drastically.

\subsection{Lack of a Proper Worksite}

Lack of a proper worksite, in this case, comprises of lack of a work place; unsuitable work place; and lack of storage space. Unsuitable work place includes worksites without a shelter and opened to hash weather (hot sun and rain), and worksites considered as unsafe and insecure. This is a general challenge among entrepreneurs in quest of starting a business. However, after discovering a place and starting operations, HEs sooner or later are faced with a similar problem when rent increases or they need relocation to bigger sites to accommodate the expansion. Bakeine (2009) argues that the majority of HE entrepreneurs do have premises to operate in, but their key setback is the high cost of rent. With increasing costs in most SSA economies, landlords periodically increase rent, and many of the HEs cannot pay such rapidly increasing rent.

\subsection{Lack of Business Knowhow}

The lack of business knowhow unfolds in two main branches. These are: (a) finding buyers; (b) problem of bad debts (Bakeine, 2009). Lack of buyers is one of the main challenges of HEs on the lookout to sell their goods and services. The concerns, in this case, are insufficient buyers, high level of competition for the limited buyers 
available, and target market contains only low-income earners. This problem would have been avoided if HEs could undergo a basic study of their target market to know the gap available, level of competition, and location of buyers. Many of the entrepreneurs, for lack of advice and training, do not see the need to engage in a study of the market before commencing operations (Kayanula \& Quartey, 2000). Bad debts arise out of regular business transactions with customers, who are short of the cash. This problem seems to be common with new-entrant enterprises, which are inexperienced to deal with this issue of credit purchases. Usually, customers negotiate for credit and promise to pay back later. They (customers) end up taking too long to pay or not paying. This leaves the HE without the goods and cash as well (Bakeine, 2009).

\subsection{Lack of Access to Appropriate Technology}

This is a challenge faced by HEs that are unable to upgrade their technology due to, lack of finance and unavailability of the desired technology. One may think that this is only a problem to the rural-based HEs but it hurts the urban ones as well. For example, a study by Bakeine (2009) revealed that 66 percent and 67 percent of HEs in urban and rural localities respectively lack access to appropriate technology. Although all enterprises face the above challenges, HEs are usually ignored and more attention is given to larger enterprises. According to Kayanula and Quartey (2000), larger enterprises already receive massive support through finance, direct subsidies, tax policy, and general trade and HEs tend to be more constrained. This was also affirmed by Fox and Sohnesen (2012) concerning HEs in low-income SSA countries.

\subsection{Greatest Obstacle to HEs Operation in Ghana}

From the IFS (2013), the enterprises were asked to point out the greatest obstacle affecting the expansion and growth of the enterprises. 36 enterprises (about 5\%) stated that they had no obstacle. The obstacles indicated by the enterprises from highest to least are limited access to loans (264 HEs), power supply problem (224 HEs), limited access to land (101 HEs), water supply problem (67 HEs), crime and corruption (19 HEs), and limited technology and inadequate labour (18 HEs). Limited access to loans which was indicated by 264 enterprises (about $36 \%$ ) is the greatest obstacle hindering the growth of the majority of the enterprises. This finding confirms the findings of other empirical studies (Osei-Assibey, 2014; Gariba, 2015) in Ghana indicating financial constraint as the principal challenge of enterprises. Fig 2 below shows the bar chart of the main obstacles facing HEs in Ghana.

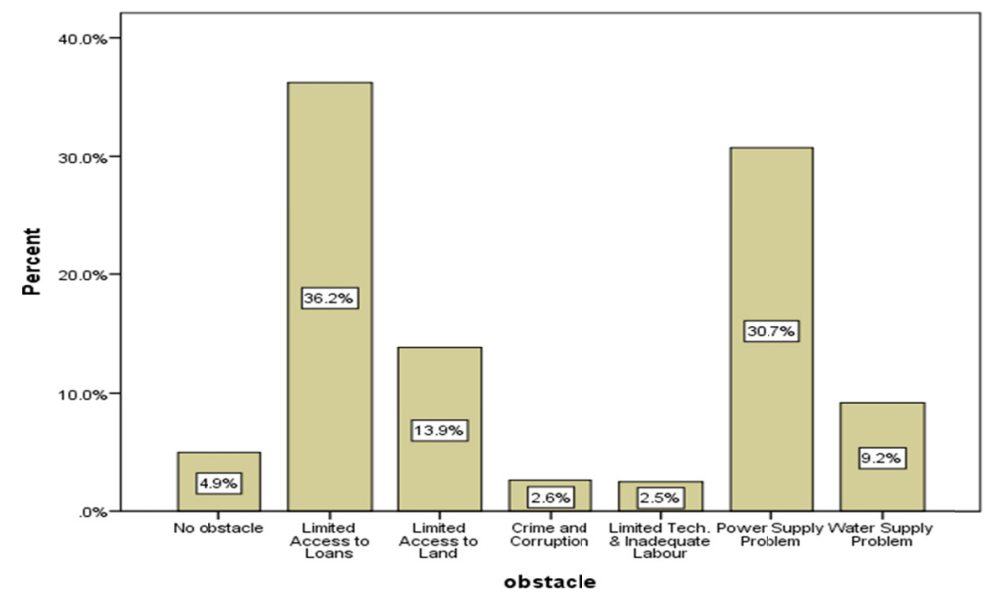

Figure 2. Bar Chart showing the Obstacles facing the HEs

\subsection{Inter-Linkage between HEs and the Financial Sector}

Since most of the enterprises indicated access to credit as the major obstacle in their operation, there is the need to look at the relationship between the Ghanaian financial sector and the HE sector.

Recent studies like Amissah and Gyeke-Dako (2016) have shown that the financial sector has a significant impact on the private sector of which the informal enterprise sector is of no exception. The financial sector provides informal enterprises with financial services such as long- and short-term loans, overdrafts, among others. HEs are faced with the option of going to the two main branches of the Ghanaian financial sectors; formal and informal sectors. Each of these sectors is characterised by different features which affect a HE's choice of where to seek for financial aid. The informal sector often requires little or no information or condition 
when it comes to loan acquisition. However, loans from such sources are limited and often come at high interest rates (Aryeetey, 1992; Amissah \& Gyeke-Dako, 2016). On the other hand, there is no financial constrain when it comes to the formal financial sector. But such loans always come with complex paperwork and collateral requirements making it difficult for HEs to acquire loans from such sources.

According to the GSS (2014), among the Non-Farm Enterprises that applied for credit, $31 \%$ of them had access to bank loans. In the informal financial sector, we see that loans from family and friends were the highest (29\%) and those from Money Lenders were the least (8\%). This is because loans from money lenders come at a high-interest rate and it is usually the last resort for most entrepreneurs. The pie chart shows that most of the HEs have access to informal loans and are more active in the informal financial sector. From fig 3, we see that the formal financial sector shows $30 \%$ of access to loans whilst the informal sector shows $70 \%$.

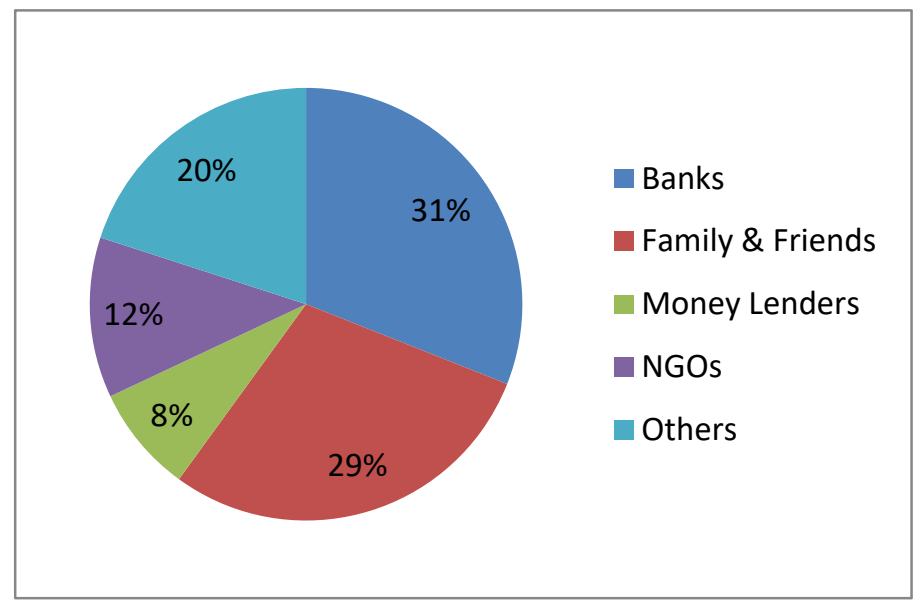

Figure 3. A Pie Chart showing the Source of Credit for Non-Farm Enterprises

A study by De la Torre, Peria and Schmukler (2010) indicated that most of the micro and small enterprises opting for the informal source of finance does not necessarily enhance greater output and revenue. They argued that it is common sense to find most of the small enterprises being financed by informal loans, but in the end, most of them fail and collapse in no time. Aryeetey (1998) also argued that informal institutions are unstable, collapse overtime and their delivery of credit is not appropriately done. In addition, Amissah and Gyeke-Dako (2016) stipulated that formal financing of small enterprises are better than informal financing. They found that in Ghana, there is a positive significant relationship between formal financing and enterprise performance and also added that, although formal financing has a higher impact on the performance of large firms it also has a high significant impact on MEs and HEs performance as well. This is because the formal institutions closely monitor the performance of the small enterprises to prevent defaulting of the loans. But this does not mean that informal financing and self-financing is not important.

The decision as to which sector to apply for a loan goes beyond only growth and expansion of the enterprise. It also involves proximity to which of the financial sectors; the urgency of the demand for the loan; and also the requirements the lenders may demand. Aryeetey (1992) stated that informal loans are often demanded after the rejection of bank credit application and this is because bank credit is cheaper than informal loans (except for loans from friends). Although the financial market in Ghana is differentiated, the demand for loans is not exclusive of each sector. In applying for loans from the formal and informal financial sector, sometimes these applications serve as a substitute for one another, but other times they serve as complements (Munira, 2013).

\section{Conclusions and General Recommendations}

This section will elaborate on some strategies which can be used to finance HEs. Financing of HEs may vary from country to country depending on the nature and structure of the HE sector (World Bank, 2018). Therefore, the strategies in this study were drawn based on the descriptive statistics and the nature of HEs in Ghana. In order to properly make these strategies efficient, the various actors have to be involved. The entrepreneurs, the financial institutions, the government, and other NGOs must all know what precisely they ought to do to help in closing the financial gap facing HEs. 


\subsection{Entrepreneurs}

Entrepreneurs should understand the dynamics of loan application. They need to know that no lender would invest in a business without potential. So, there is the need for HEs to present themselves as viable enterprises and be convincing enough by proving to be creditworthy. They can do this by preparing project proposals and keeping records. The entrepreneurs should also embark on training to improve their skills in order to make them more efficient in the management and allocation of resources. Also, entrepreneurs should be educated on the need for keeping financial records because the majority $(67 \%)$ of them do not keep financial records. Since approximately $60 \%$ of the entrepreneurs in the HE sector have at most basic education, there is the need to educate them on the importance of keeping a financial record. They may see it as challenging, but they can adopt the simple bookkeeping method which reports on inventory and profit. Furthermore, when entrepreneurs were asked what would increase their chances of accessing a loan, over $70 \%$ indicated that by formalizing their activities. This increases their chances of accessing a loan by signaling to the lender their creditworthiness.

\subsection{Financial Institutions}

The formal financial institutions (banks) need to see HEs as a strategic sector for expansion of their operations. It is a sector with great potentials and if the banks see it as such they will also benefit greatly. Although it is a sector full of risk, the profits and benefits are undeniable. The banks, therefore, need to ease down a bit on the issue of collateral and also focus on the potential of the business proposal of the entrepreneur. They need to also make the repayment conditions quite flexible by increasing the maturity period of loans for HEs. Also, lending is not the only service banks can provide for HEs. The banks should go beyond the lending services by organising training programmes to educate entrepreneurs who bank with them and those who do not. They can educate them on the loan application process, writing of a business plan, capacity building, how to keep financial records, and many more. The experience of formal financial institutions over the years by working with large enterprises far exceed that of the informal financial sector, hence making them the best choice for a long-term financial relationship. Their understanding of enterprise survival skills, surviving start-ups and other enterprise related issues will certainly be beneficial to the growth of HEs. This will improve the HEs' survival rate, by making them more profitable and less credit constrained. The banks will also benefit since those entrepreneurs will recommend them to their colleague entrepreneurs.

\subsection{Government and NGOS}

The government should provide education for entrepreneurs of HEs on how to manage their business in a manner to attract investments. The government should focus on improving the financial literacy of entrepreneurs. This will help entrepreneurs take advantage of the available financial services and also avoid risks. Depending on the level of sufficient financial education, entrepreneurs can then take advantage of the existing government and non-government financial schemes. In most cases, entrepreneurs in the informal sector are not aware of the various financial options at their disposal. Over 53\% of HEs have been in business for 5 years or more but they are ignorant of the available financial schemes except for bank loans. There are the likes of Promotion of Small and Micro Enterprise Fund (PSME), Support for Private Enterprise Expansion and Development (SPEED), and Funds for Small and Medium Scale Enterprise Development (FUSMED), but most of the entrepreneurs are ignorant. This is because often times awareness of these schemes is done only in a few capital cities, such as Accra and Kumasi. The issue of awareness has been talked about in most research (Abor \& Biekpe, 2006), but the problem is the scope of awareness. The government and NGOs who provide these schemes should embark on an awareness which goes beyond the capital cities to small towns and villages.

One of the main reasons for HEs' credit constraint is because of the nature of risk which is associated with their operations. Therefore, the government should encourage the formation of enterprise associations to serve as a credit guarantee for those that may apply for loans. Through a large number of members of these associations, the risk related to HE loans can then be spread out. The study reveals that operating a HE serves as the only livelihood of majority (96\%) of the household. Hence, the government needs to produce an enabling environment for more HEs to spring up since this can solve the problem of unemployment and eradicate poverty. The government must focus on providing uninterrupted power and water supply. This is because power and water are also major obstacles facing HEs. By this their quest for obtaining loans to solve power and water problems is curtailed. This will indirectly prevent the need for the loan for some HEs. 


\section{References}

Abor, J., \& Biekpe, N. (2006). Small Business Financing Initiatives in Ghana. Problems and Perspectives in Management, 4(3), 69-77.

Abor, J., \& Quartey, P. (2010). Issues in SMEs in Ghana and South Africa. International Research Journal of Finance and Economics, (39), 218-228.

Alhassan, F., \& Sakara, A. (2014). Socio-Economic Determinants of Small and Medium Enterprises' (SMEs) Access to Credit from the Barclays Bank in Tamale-Ghana. International Journal of Humanities and Social Science Studies, 1(2), 26-36.

Amissah, E., \& Gyeke-Dako, A. (2016). Formal and informal finance: firm growth in Ghana, Final report. International Growth Centre: F-33204-GHA-1

Aryeetey, E. (1992). The relationship between the formal and informal sectors of the financial market in Ghana the African Economic Research Consortium. AERC Research Paper No. 10

Aryeetey, E. (1998). Informal Finance for Private Sector Development in Africa. African Development Report, Institute of Statistical, Social and Economic Research, Ghana.

Aryeetey, E. T., Baah-Nuakoh, A., Duggleby, T., Hettige, H., \& Steel, W. F. (1994). Supply and Demand for Finance of Small Enterprises in Ghana. World Bank Discussion Paper No. 251. Washington D.C.: World Bank. https://doi.org/10.1596/0-8213-2964-2

Aryeetey, E., \& Gockel, F. (1991). Mobilizing Domestic Resource for Capital Formation in Ghana; The Role of Informal Financial Sector. AERC Research Paper, No. 3, AERC, Nairobi.

Baah-Nuakoh, A. (2003). Studies on the Ghanaian Economy: the Industrial Sector, 3, Accra: Woeli Publication.

Bakeine, A. (2009). Raising Productivity and Reducing the Risk of Household Enterprise: Survey Report, Uganda Country Study. World Bank.

Barrett, C. B., Reardon, T., \& Webb, P. (2001). Nonfarm income diversification and household livelihood strategies in rural Africa: concepts, dynamics, and policy implications. Food Policy, 26(4). https://doi.org/10.1016/S0306-9192(01)00014-8

De la Torre, A., Peria, M. S., \& Schmukler, S. (2010). Bank Involvement with SMEs: Beyond Relationship Lending. Journal of Banking and Finance, 34, 2280-93. https://doi.org/10.1016/j.jbankfin.2010.02.014

EGC-ISSER. (2015). The Living Standards Measurement Study (LSMS): Basic Information on Survey. Institute of Statistical, Social and Economic Research (ISSER), University of Ghana.

Fields, G. S. (2012). Working Hard, Working Poor: A global journey. New York: Oxford University Press. https://doi.org/10.1093/acprof:oso/9780199794645.001.0001

Fox, L., \& Gaal M. S. (2008). Working out of Poverty: Job Creation and the Quality of Growth in Africa. The World Bank, Washington, DC. https://doi.org/10.1596/978-0-8213-7442-9

Fox, L., \& Sohnesen, T. P. (2012). Household Enterprises in Sub-Saharan Africa Why They Matter for Growth, Jobs, and Livelihoods. Policy Research Working Paper Series, The World Bank, (August), 53. https://doi.org/10.1596/1813-9450-6184

Gariba, F. (2015). Small and Medium-Sized Enterprises (SMEs) Access to Credit in Ghana: Determinants and Challenges. Thesis Submitted to the University Of Ghana, Mphil Economics (10226179).

Ghana Statistical Service (GSS). (2014). Ghana Living Standards Survey, Round 6 (GLSS6): Main Report.

Haggblade S., Hazel, P., \& Reardon, T. (2010). The Rural Non-farm Economy: Prospects and Poverty Reduction. World Development, 38. https://doi.org/10.1016/j.worlddev.2009.06.008

Informal Survey (IFS). (2013). Ghana Informal Enterprise Survey. World Bank.

International Labour Organization (ILO). (2011). Statistical Update on Employment in the Informal Economy. Department of Statistics, Geneva, June.

Kayanula, D., \& Quartey, P. (2000). The Policy Environment for Promoting Small and Medium-sized Enterprises in Ghana and Malawi. Finance and Development Research Programme Working Paper Series, Paper No. 15.

Munira, A. M. (2013). Formal and Informal Credit Demand by Rice Farmers in the Northern Region of Ghana. Thesis Submitted to the University of Ghana, Mphil Economics (10362172). 
National Bureau of Statistics (NBS). (2011). Household Enterprises in Nigeria. Report on Living Standards Measurement Study - Integrated Surveys on Agriculture (LSMS-ISA) project, 7-8.

Nkuah, J. K., Tanyeh, J. P., \& Gaeten, K. (2013). Financing Small and Medium Enterprises (SMEs) In Ghana: Challenges and Determinants in Accessing Bank Credit. International Journal of Research in Social Sciences, 2(3), 12-25.

NVTI. (2009). About National Vocational Training Institute (NVTI). Retrieved from http://www.nvtighana.org/AboutUs.aspx

Osei-Assibey, E. (2014). The Rural financial System in Ghana: What determines Access and Sources of Finance for rural Non-Farm Enterprises? In Readings on Key Economic Issues in Ghana, Social Science Series, 4, Department of Economics, University of Ghana, Legon.

Quainoo, A. (2011). Raising Productivity and Reducing the Risk of Household Enterprise: Survey Report, Ghana Country Study. World Bank.

Samphantharak, K., \& Townsend, R. M. (2012). Measuring the return on household enterprise: What matters most for whom? Journal of Development Economics, 98(1), 58-70. https://doi.org/10.1016/j.jdeveco.2011.09.001

Steel, W. F., \& Webster, L. M. (1991). Small Enterprises in Ghana: Responses to Adjustment. Industry Series Paper, No. 33. The World Bank Industry and Energy Department, Washington.

Stephanou, C., \& Rodriguez, C. (2008). Bank Financing to Small and Medium-Sized Enterprises (SMEs) in Colombia. Policy Research Working Paper No. 4481. Washington D. C.: World Bank. https://doi.org/10.1596/1813-9450-4481

Weston, J. F., \& Copeland, T. E. (1998). Managerial Finance. New York: CBS College Publishing.

WIEGO. (2008). Informal Economy: Policies \& Programmes for Household Enterprises in Africa. Retrieved from http://www.wiego.org/informal-economy/policies-programmes-household-enterprises-africa

World Bank. (2012). Household Enterprises in Mozambique: Key to Poverty Reduction, but not a Key Agenda? Preliminary Draft: World Bank Africa Regional Project.

World Bank. (2018). Improving SMEs' access to finance and finding innovative solutions to unlock sources of capital. Retrieved from https://www.worldbank.org/en/topic/ smefinance

\section{Copyrights}

Copyright for this article is retained by the author(s), with first publication rights granted to the journal.

This is an open-access article distributed under the terms and conditions of the Creative Commons Attribution license (http://creativecommons.org/licenses/by/4.0/). 